\title{
IMPLEMENTASI METODE SVM UNTUK MEMPREDIKSI HASIL PANEN TANAMAN PADI
}

\author{
Agus Setia Budi ${ }^{1}$, Purnomo Hadi Susilo ${ }^{2}$ \\ Teknik Informatika, Fakultas Teknik, Universitas Islam Lamongan \\ Jl. Veteran No.53 A Lamongan Jawa Timur \\ E-mail: geniusbudi@unisla.ac.id ${ }^{1}$,purnomo@unisla.ac.id ${ }^{2}$
}

\begin{abstract}
ABSTRAKS
Sektor pertanian yang terdapat di Indonesia sangatlah tergantung pada sumber air dari irigasi waduk dan hujan. Beberapa keadaan tanah pertanian di Indonesia sebagian besar merupakan sawah dan tambak tadah hujan. Tanaman yang ada di Indonesia dapat berkembang dengan baik yaity dengan mengandalkan air dari hujan dan irigasi. Hal inilah yang menjadikan kondisi cuaca sangat berpengaruh terhadap banyak sedikitnya jumlah panen tanaman padi para petani. Kondisi keadaan cuaca yang sering berubah-ubah secara tidak menentu sering membuat para petani mengalami kegagalan panen tanaman padi. Panen tanaman padi di Indonesia megalami penurunan sebesar 7,76\% pada tahun 2019 dibandingkan dengan hasil panen tanaman padi pada tahun 2018 (Badan Pusat Statistik). Cara yang dapat dilakukan agar dapat mengurangi penurunan hasil panen tanaman padi yaitu salah satunya dengan menerapkan metode SVM untuk memprediksi hasil panen padi. Data penelitian yang dilakukan diambil dari situs resmi pertanian melalui web (https://www.pertanian.go.id/home/?show=page\&act=view\&id=61). Variabel yang digunakan meliputi 1) propinsi; 2) tahun; 3) luas lahan; dan 4) produksi. Data yang digunakan sebanyak 170, dengan jumlah 130 sebagai data training dan 40 sebagai data testing. Data-data tersebut kemudian diolah dan dilakukan normalisasi, selanjutnya dilakukan training dan diprediksi menggunakan metode SVM. Hasil penelitian menunjukkan data MAPE sebesar 6635,53\% dan RMSE 1094810,74 menggunakan data asli tanpa normalisasi, dan MAPE sebesar 9427,71\% dan RMSE 0,017 saat data telah dinormalisasi.
\end{abstract}

Kata Kunci: Sistem Prediksi, Metode SVM, Hasil Panen, Tanaman Padi

\begin{abstract}
The agricultural sector in Indonesia is highly dependent on water sources from reservoir irrigation and rain. Some conditions of agricultural land in Indonesia are mostly rice fields and rainfed ponds. Plants in Indonesia can develop well by relying on water from rain and irrigation. This is what makes the weather conditions very influential on the amount of rice harvested by the farmers. Weather conditions that often fluctuate erratically often make farmers experience rice crop failure. The rice crop harvest in Indonesia decreased by $7.76 \%$ in 2019 compared to the rice crop yield in 2018 (Central Statistics Agency). One way that can be done in order to reduce the decline in rice yields is by applying the SVM method to predict rice yields. The research data was taken from the agricultural official website via the web(https://www.pertanian.go.id/home/?show=page \&act=view\&id=61). The variables used include 1) province; 2 years; 3) land area; and 4) production. The data used is 170, with 130 as training data and 40 as testing data. The data is then processed and normalized, then training is carried out and predicted using the SVM method. The results showed that MAPE data was $6635.53 \%$ and RMSE was 1094810.74 using original data without normalization, and MAPE was $9427.71 \%$ and RMSE 0.017 when the data had been normalized.
\end{abstract}

Keywords: Prediction System, SVM Method, Harvest, Rice Plants

\section{PENDAHULUAN}

Produksi hasil panen tanaman padi di Indonesia telah mengalami penurunan 700,05 ribu hektar atau sebesar 6,15\% pada tahun 2019 dibandingkan pada tahun 2018 (Badan Statistik Indonesia). Pada tahun 2019 hasil panen padi yaitu sebesar 54,60 juta ton dan mengalami penurunan sebesar 4,60 juta ton atau $7,76 \%$. Hal ini yang membuat pemerintah melakukan import beras agar dapat menjadi salah satu jalan keluar untuk mecukupi kebutuhan pangan [2]. Produktivitas hasil panen tanaman padi menurun dikarenakan mengalami perubahan iklim atau cuaca, dan terjadilah perubahan unsur hara yang ada pada tanah. Masalah ini dapat diselesaikan yaitu petani harus melakukan antisipasi dan merencanakan jadwal tanam yang disesuaikan dengan kondisi cuaca terjadi pada saat ini [3]. Alternatif lain yang dapat dilakukan agar dapat menghasilkan produksi panen tanaman padi yaitu dengan membuat modelmodel tanam berikut: 1) legowo (30x25xlarikan); 2) legowo (30x25x12,5); 3) legowo (30x20xlarikan); 4) dan 5) legowo (30x20x10). Model-model tanam tersebut dapat digunakan untuk meningkatkan hasil tanaman padi gogo varietas Situ Patenggang [4]. 
Padi merupakan salah satu sumber makanan pokok bagi beberapa masyarakat di Indonesia. Padi tersebut kemudian dapat diproses dan akan menghasilkan sebuah beras yang mengandung banyak karbohidrat. Padi juga salah satu makanan yang menjadi sumber karbohidrat dan sumber utama yang dikonsumsi mayoritas masyarakat di Malang maka dikembangkanlah suatu sistem aplikasi peramalan hasil panen padi dengan metode Support Vector Regression (SVR). Aplikasi tersebut dapat memberikan hasil MAPE sebesar 10,133\% [5]. Selain menggunakan metode SVR, agar dapat melakukan estimasi hasil panen tanaman padi dapat juga dilakukan dengan menggunakan algoritma regresi linear berganda. Hasil prediksi tanaman dengan menggunakan metode regresi linear berganda standart errornya sebesar 206,3075 [6]. Metode lain yang dapat digunakan yaitu KNN untuk memprediksi hasil panen tanaman padi, dengan nilai absolute error sebesar 80876,83 [7].

Indonesia merupakan salah satu negara agraris yang hasil pertanian terbesarnya yaitu tanama padi. Di Indonesia padi merupakan bahan pokok yang digunakan sebagai sumber makanan utama bagi masyarakatnya. Hal ini yang menjadi alasan bahwa hasil panen tanaman padi di Indonesia tidak boleh turun. Perlu dikembangkan sebuah sistem tertentu yang dapat mengestimasi hasil produksi tanaman padi untuk mengatasi penurunan hasil tanaman padi tersebut. Salah satu cara yang dapat dilakukan yaitu dengan mengembangkan sebuah aplikasi sistem prediksi dengan menggunakan metode yang dapat digunakan untuk estimasi hasil panen tanaman padi adalah Support Vector Machine [5, 8]. Tujuan penelitian ini yaitu melakukan sebuah prediksi hasil panen padi dengan metode SVM agar dapat membantu upaya pemerintah dalam menentukan kebijakan di waktu selanjutnya dalam menangani penurunan hasil panen tanaman padi.

\section{METODE PENELITIAN}

Pada penelitian ini menggunakan data hasil panen tanaman padi di Indonesia. Data tersebut kemudian olah agar dapat diketahui variabel yang dapat digunakan dalam sistem prediksi dengan metode SVM. Hasil pengolahan data tersebut kemudian dipetakan menjadi beberapa varabel, yaitu propinsi, tahun, luas lahan (luas tanah yang ditanami padi), produksi (hasil panen padi pertahun), dan produktivitas (hasil panen dibagi luas lahan). Data tersebut terdiri dari 34 propinsi di Indonesia yaitu mulai tahun 2014-2018. Total data sebanyak 170 baris, kemudian dibagi menjadi 130 sebagai data training, dan 40 baris sebagai data testing. Data tersebut dapat diambil dari website resmi berikut: https://www.pertanian.go.id/home/?show=page \&act $=$ view\&id=61.

Data yang yang didapatkan kemudian dilakukan normalisasi data dengan Persamaan atau rumus dibawah berikut [1] $v_{-} n e w=\frac{v-v_{-} \min }{v_{-} \text {maks }-v_{-} \min } *\left(v_{-} n e w_{-} m a k s-v_{-} n e w_{-} \min \right)$

\subsection{Analisa Sistem Berjalan}

Dataset 130 baris yang merupakan data training tersebut terdiri dari variabel input yaitu propinsi, tahun, luas lahan dan variabel outputnya adalah produksi atau hasil panen. Kemudian dilakukan training dengan algoritma SVM, hasil training tersebut berupa persamaan garis yang terdiri dari bobot dan bias. Selanjutnya data testing diujicoba untuk menghasilkan data prediksi kemudian dihitung nilai MAPE [5] dan RMSE [9]. Adapun alur secara detailnya dapat dilihat pada Gambar 1.

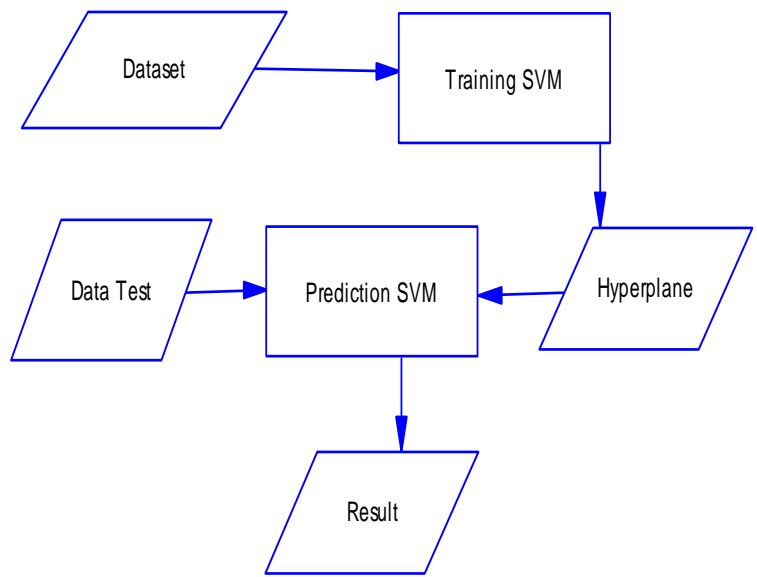

\section{Gambar 1. Alur Sistem Prediksi metode SVM}

Agar hasil prediksi lebih akurat dan hasilnya lebih baik, maka data input dilakukan normalisasi terlebih dahulu dengan rumus Persamaan 1. Kemudian selanjutnya data dari hasil normalisasi dilakukan training dengan metode SVM dan data testing diujicoba, yang hasilnya merupakan hasil akhir yang berupa data prediksi (Lihat Gambar 2).

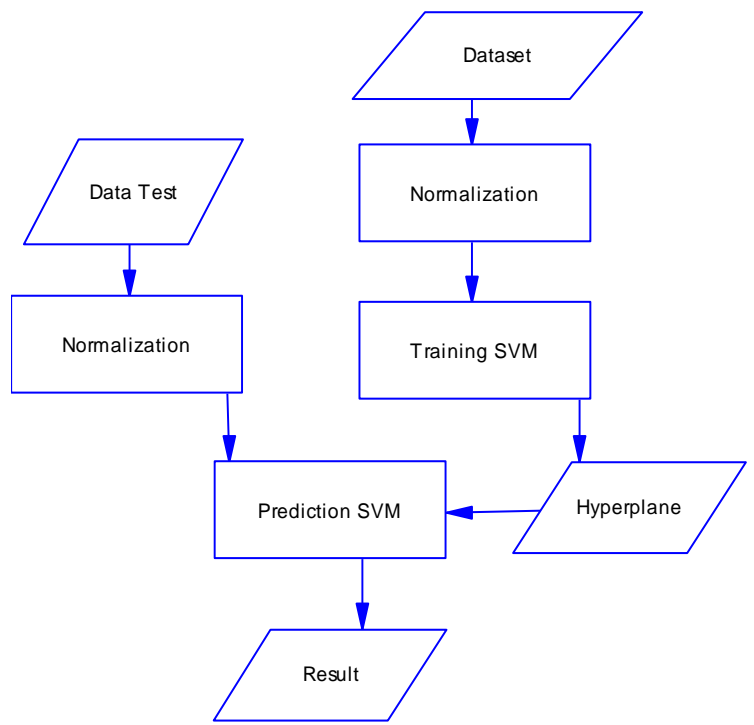

Gambar 1. Alur Sistem Prediksi metode SVM dengan Normalisasi 
Rumus persamaan yang dapat digunakan untuk menghitung nilai error MAPE dan RMSE.

$$
\begin{aligned}
& M A P E=\sum_{i=1}^{n}\left|\frac{t_{i}-y_{i}^{\prime}}{y_{i}^{\prime}}\right| x 100 \% \\
& R M S E=\sqrt{\frac{1}{n} \sum\left(t_{i}-y_{i}^{\prime}\right)^{2}}
\end{aligned}
$$

Keterangan: $\mathrm{t}=$ target atau data nyata

$$
\begin{aligned}
& \mathrm{y}^{\prime}=\text { data hasil prediksi } \\
& \mathrm{n}=\text { total data tes seluruhnya. }
\end{aligned}
$$

\subsection{Dataset dan Normalisasi}

Data yang ada pada Tabel 1 propinsi sejumlah 34 yang ada di Indonesia dengan simbol angka, 1 berarti propinsi Aceh, dan simbol angka 2 adalah propinsi Sumatera Utara. Kemudian data tahun dimulai dari tahun 2014 sampai tahun 2018. Luas lahan adalah luas tanah yang ditanami tanaman padi saja dengan satuan hektar. Produksi adalah hasil panen tanaman padi setiap tahunnya dalam satuan ton. Data yang ada pada Tabel 2 merupakan data yang sudah dilakukan normalisasi terlebih dahulu dengan menggunakan rumus Persamaan 1. Setiap variabel dihitung dan dicari nilai maksimumnya, minimum, kemudian dihitung nilai baru dengan rentang [0 1].

Table 1. Dataset

\begin{tabular}{lcll}
\hline Propinsi & Tahun & $\begin{array}{l}\text { Luas } \\
\text { Lahan (Ha) }\end{array}$ & $\begin{array}{l}\text { Produktivitas } \\
\text { (ton) }\end{array}$ \\
\hline 1 & 2014 & 376137 & 1820062 \\
1 & 2015 & 461060 & 2331046 \\
1 & 2016 & 429486 & 2205056 \\
1 & 2017 & 470351 & 2494613 \\
1 & 2018 & 463485 & 2516221 \\
2 & 2014 & 717318 & 3631039 \\
2 & 2015 & 781769 & 4044829 \\
\hline
\end{tabular}

Table 2. Data Normalisasi

\begin{tabular}{lccc}
\hline Propinsi & Tahun & $\begin{array}{l}\text { Luas } \\
\text { Lahan (Ha) }\end{array}$ & $\begin{array}{l}\text { Produktivitas } \\
\text { (ton) }\end{array}$ \\
\hline 0.00 & 0.00 & 0.16 & 0.13 \\
0.00 & 0.25 & 0.20 & 0.17 \\
0.00 & 0.50 & 0.19 & 0.16 \\
0.00 & 0.75 & 0.21 & 0.18 \\
0.00 & 1.00 & 0.20 & 0.18 \\
0.03 & 0.00 & 0.31 & 0.27 \\
0.03 & 0.25 & 0.34 & 0.30 \\
\hline
\end{tabular}

2.3 Hasil dan Pembahasan

Prediksi Hasil Panen Padi Dengan Metode SVM

Table 3. Hasil Training data Bobot dan Bias

\begin{tabular}{ll}
\hline Bobot & Bias \\
\hline-31.67 & -1291356.6 \\
-2.42 & \\
6.69 & \\
\hline
\end{tabular}

Hasil prediksi dari metode SVM dapat dilihat pada Tabel 4. Data aktual adalah data testing yang

\begin{tabular}{|c|c|}
\hline Data Real & Hasil Prediksi \\
\hline 5426097 & 5657146 \\
\hline 5471806 & 5683930 \\
\hline 5727081 & 6252905 \\
\hline 6055404 & 6652682 \\
\hline 6196737 & 6477784 \\
\hline 657617 & -358267 \\
\hline 660720 & -358457 \\
\hline 695329 & -139553 \\
\hline 711401 & -151056 \\
\hline 716156 & -152851 \\
\hline 314704 & -877969 \\
\hline 331220 & -898178 \\
\hline 344869 & -854510 \\
\hline 350193 & -780893 \\
\hline 350256 & -778930 \\
\hline 449621 & -666296 \\
\hline 461844 & -672189 \\
\hline 548536 & -485294 \\
\hline 667100 & -355442 \\
\hline 751531 & -170172 \\
\hline 102761 & -1152631 \\
\hline 117791 & -1155856 \\
\hline 99088 & -1153525 \\
\hline 104716 & -1125136 \\
\hline 132852 & -1087500 \\
\hline 72074 & -1155545 \\
\hline 75265 & -1153902 \\
\hline 82213 & -1128322 \\
\hline 84037 & -1113520 \\
\hline 101054 & -1096010 \\
\hline 27665 & -1251275 \\
\hline 30219 & -1249312 \\
\hline 27840 & -1254690 \\
\hline 29516 & -1252479 \\
\hline 27736 & -1252575 \\
\hline 196015 & -993117 \\
\hline 181769 & -1020795 \\
\hline 233599 & -959642 \\
\hline 257888 & -946030 \\
\hline 288335 & -891356 \\
\hline
\end{tabular}
akan diujicoba, sedangkan data hasil prediksi adalah data perhitungan persamaan hasil training SVM.

Table 4. Hasil Prediksi Data Training 
Dalam melakukan prediksi hasil panen tanaman padi dengan metode SVM didapatkan nilai MAPE sebesar 6635,53\%, dan RMSE sebesar 1094810,74. Proses prediksi dengan metode SVM menggunakan kernel linear dengan hasil dari training adalah bobot dan bias yang digunakan untuk memprediksi data testing. Adapun data Bobot dan bias dapat dilihat pada Tabel 3.

\section{Prediksi Hasil Panen Padi Dengan Metode SVM Data Normalisas}

Prediksi dengan Metode SVM yang datanya dinormalisasi terlebih dahulu hasil nilai MAPE sebesar 9427,714, dan nilai RMSE sebesar 0,017. Hasil dari training SVM dapat dilihat pada Tabel 5. Hasil training berupa bobot dan bias. Data hasil ujicoba testing dapat dilihat pada Tabel 6. Proses hasil perhitungan MAPE dan RMSE berdasarkan pada Tabel 6 yaitu, nilai data real dikurangi dengan nilai hasil prediksi.

Table 5. Normalisasi Data Bobot dan Bias

\begin{tabular}{ll}
\hline Bobot & Bias \\
\hline-0.00243 & -0.0172011 \\
0.00293 & \\
0.97071 & \\
\hline
\end{tabular}

Table 6. Data Hasil Prediksi setelah Normalisasi

\begin{tabular}{|c|c|}
\hline Data Real & Hasil Prediksi \\
\hline 0.40 & 0.423 \\
\hline 0.40 & 0.425 \\
\hline 0.42 & 0.462 \\
\hline 0.44 & 0.488 \\
\hline 0.45 & 0.478 \\
\hline 0.05 & 0.040 \\
\hline 0.05 & 0.041 \\
\hline 0.05 & 0.056 \\
\hline 0.05 & 0.056 \\
\hline 0.05 & 0.056 \\
\hline 0.02 & 0.007 \\
\hline 0.02 & 0.007 \\
\hline 0.03 & 0.010 \\
\hline 0.03 & 0.016 \\
\hline 0.03 & 0.017 \\
\hline 0.03 & 0.021 \\
\hline 0.03 & 0.021 \\
\hline 0.04 & 0.034 \\
\hline 0.05 & 0.043 \\
\hline 0.06 & 0.055 \\
\hline 0.01 & -0.010 \\
\hline 0.01 & -0.010 \\
\hline 0.01 & -0.009 \\
\hline
\end{tabular}

\begin{tabular}{ll}
0.01 & -0.006 \\
0.01 & -0.003 \\
0.01 & -0.011 \\
0.01 & -0.010 \\
0.01 & -0.007 \\
0.01 & -0.006 \\
0.01 & -0.004 \\
0.00 & -0.017 \\
0.00 & -0.016 \\
0.00 & -0.015 \\
0.00 & -0.015 \\
0.00 & -0.014 \\
0.01 & 0.000 \\
0.01 & -0.001 \\
0.02 & 0.003 \\
0.02 & 0.005 \\
0.02 & 0.009 \\
\hline
\end{tabular}

Pada Tabel 7 menjelaskan bahwa hasil akurasi MAPE dan RMSE dari prediksi hasil panen tanaman padi dengan metode SVM, SVM regresi, dan regresi linear. Pada kolom SVM yaitu menggunakan fungsi fitrsvm, dan SVM regresi yaitu menggunakan fungsi fitrlinear, dan regresi linear yaitu menggunakan fungsi regress

Table 7. Hasil Akurasi

\begin{tabular}{crcc}
\hline Type & SVM & SVM Regresi & $\begin{array}{c}\text { Regresi } \\
\text { Linear }\end{array}$ \\
\hline MAPE & 6635,53 & 3008.31 & 4024 \\
RMSE & 1094810,74 & 1319401.1081 & 104449563,2 \\
\hline
\end{tabular}

\section{KESIMPULAN}

Pengembangan sistem prediksi hasil panen tanaman padi dengan menggunakan metode SVM dalam memprediksi hasil panen padi dapat dikatan berhasil dengan nilai akurasi yang tinggi. Hal ini dapat dibuktikan bahwa hasil prediksi dengan nilai MAPE sebesar 6635,53, dan RMSE sebesar 1094810,74. Hasil prediksi dengan metode SVM juga digunakan untuk memprediksi hasil panen tanaman padi dengan cara normalisasi data terlebih dahulu yaitu dengan nilai MAPE sebesar 9427,714 dan RMSE sebesar 0,017.

\section{PUSTAKA}

E. Hartanto, D. Sitorus and A. Wanto, "Analisis Jaringan Saraf Tiruan untuk Prediksi Luas Panen Biofarmaka di Indonesia," SEMANTIK, vol. 4, no. 1, pp. 49-56, 2018.

F. Maspiyanti and M. I. Fanany, "Klasifikasi Fase Pertumbuhan Padi Berdasarkan Citra 
Hiperspektral dengan Modifikasi Logika Fuzzy," Jurnal Pengindraan Jauh, vol. 10, no. 1, pp. 41-48, 2013.

H. Herminingsih, "Hubungan Adaptasi Petani Terhadap Perubahan Iklim dengan Produktivitas Tembakau pada Lahan Sawah dan Tegalan di Kabupaten Jember," JSEP, vol. 7, no. 2, pp. 31-44, 2014.

S. Putra, "Pengaruh Jarak Tanam Terhadap Peningkatan Hasil Padi Gogo Varietas Situ Patenggang," Agrin, vol. 15, no. 1, pp. 54-63, 2011 .

D. A. Mardhika, B. D. Setiawan and R. C. Wihandika, "Penerapan Algoritma Support Vector Regression Pada Peramalan Hasil Panen Padi Studi Kasus Kabupaten Malang," Jurnal Pengembangan Teknologi Informasi dan Ilmu Komputer, vol. 3, no. 10, pp. 94029412, 2019.

E. I. A. Warih and Y. Rahayu, "PENERAPAN DATA MINING UNTUK MENENTUKAN ESTIMASI PRODUKTIVITAS TANAMAN TEBU DENGAN MENGGUNAKAN ALGORITMA LINIER REGRESI BERGANDA DI KABUPATEN REMBANG," Teknik Informatika, Fakultas Ilmu Komputer, Universitas Dian Nuswantoro, Semarang.

W. T. Panjaitan, E. Utami and H. Al-Fatta, "PREDIKSI PANEN PADI MENGGUNAKAN ALGORITMA KNEAREST NEIGBOUR," in SNATIF Universitas Muara Kudus, Kudus, 2018.

Fatkhuroji, S. Santosa and R. A. Pramunendar, "PREDIKSI HARGA KEDELAI LOKAL DAN KEDELAI IMPOR DENGAN METODE SUPPORT VECTOR MACHINE BERBASIS FORWARD SELECTION," Jurnal Teknologi Informasi, vol. 15, no. 1, pp. 61-77, 2019.

A. Mayasari and Y. Rahayu, "PENERAPAN ALGORITMA LINIER REGRESSION UNTUK MENENTUKAN ESTIMASI LUAS LAHAN PANEN TANAMAN JAGUNG TERHADAP CURAH HUJAN DAN AREA TAMBAH TANAM DI KABUPATEN REMBANG," Program Studi Teknik Informatika, Fakultas Ilmu Komputer, Universitas Dian Nuswantoro, Semarang.

R. Nuari, A. Apriliyani, Juwari and Kusrini, "IMPLEMENTASI METODE K-NEAREST NEIGHBOR (KNN) UNTUK MEMPREDIKSI VARIETAS PADI YANG COCOK UNTUK LAHAN PERTANIAN," Jurnal INFORMA Politeknik Indonusa Surakarta, vol. 4, no. 2, pp. 28-34, 2018.

D. Rohmayani, "ANALYSIS OF STUDENT TUITION FEEPAY DELAY PREDICTION USING NAIVE BAYES ALGORITHM WITH
PARTICLE SWARM OPTIMATION OPTIMAZATION (CASE STUDY : POLITEKNIK TEDC BANDUNG)," Jurnal Teknologi Informasi dan Pendidikan, vol. 13, no. 2, pp. 1-8, 2020.

E. Prasetyo, Data Mining Konsep dan Aplikasi Menggunakan Matlab, Yogyakarta: Andi, 2012.

B. Santosa, Data Mining Teknik Pemanfaatan Data untuk Keperluan Bisnis Teori dan Aplikasi, Yogyakarta: Graha Ilmu, 2007.

B. Santosa, Data Mining Terapan dengan Matlab, Yogyakarta: Graha Ilmu, 2007. 